\title{
Review Article \\ Role of Nuclear Factor Erythroid 2-Related Factor 2 in Diabetic Nephropathy
}

\author{
Wenpeng Cui, ${ }^{1}$ Xu Min, ${ }^{1}$ Xiaohong Xu, ${ }^{2}$ Bing Du, ${ }^{3}$ and Ping Luo ${ }^{1}$ \\ ${ }^{1}$ Department of Nephrology, The Second Hospital of Jilin University, Changchun, Jilin 130041, China \\ ${ }^{2}$ Department of Gynaecology and Obstetrics, The Second Hospital of Jilin University, Changchun, Jilin 130041, China \\ ${ }^{3}$ Department of Cardiology, The First Hospital of Jilin University, Changchun, Jilin 130031, China
}

Correspondence should be addressed to Bing Du; dbdavina@126.com and Ping Luo; luopingjen@163.com

Received 19 December 2016; Revised 9 February 2017; Accepted 13 March 2017; Published 23 April 2017

Academic Editor: Wei J. Liu

Copyright (c) 2017 Wenpeng Cui et al. This is an open access article distributed under the Creative Commons Attribution License, which permits unrestricted use, distribution, and reproduction in any medium, provided the original work is properly cited.

Diabetic nephropathy (DN) is manifested as increased urinary protein level, decreased glomerular filtration rate, and final renal dysfunction. DN is the leading cause of end-stage renal disease worldwide and causes a huge societal healthcare burden. Since satisfied treatments are still limited, exploring new strategies for the treatment of this disease is urgently needed. Oxidative stress takes part in the initiation and development of DN. In addition, nuclear factor erythroid 2-related factor 2 (Nrf2) plays a key role in the cellular response to oxidative stress. Thus, activation of Nrf2 seems to be a new choice for the treatment of DN. In current review, we discussed and summarized the therapeutic effects of $\mathrm{Nrf} 2$ activation on DN from both basic and clinical studies.

\section{Introduction}

According to the data from the International Diabetes Federation, the number of individuals who suffered from diabetic mellitus was 285 million in 2010, and this number will increase to 439 million in 2030. Diabetic nephropathy (DN), a serious complication of diabetic mellitus, is manifested as increased urinary protein level, decreased glomerular filtration rate (GFR), and final renal dysfunction [1]. DN is the leading cause of end-stage renal disease worldwide. Additionally, DN reduces patient's quality of life and increases the societal healthcare burdens. Various therapeutic approaches, such as glucose, lipid, and blood pressure control; renin-angiotensin system inhibitor application; and lifestyle changes, have been tried to slow the progression of $\mathrm{DN}$ [2]. However, the curative effect is not satisfactory, and the developing speed of DN is still the fastest among chronic kidney diseases (CKDs). Therefore, novel strategies for fighting against this disease are urgently needed.

The pathogenesis of DN is complicated. It is suggested that hemodynamic changes, genetic susceptibility, hyperglycemia, dyslipidemia, and oxidative stress take part in the progress and development of DN [3]. Among these issues, oxidative stress and its related inflammation and fibrosis have been reported to aggravate DN in recent years [4]. In our body, mechanisms maintaining the balance between oxidation and reduction are complicated. Nuclear factor erythroid 2-related factor 2 (Nrf2)/antioxidant-responsive element (ARE) pathway is proven to be crucial in this process $[5,6]$. Therefore, activation of Nrf2/ARE pathway seems to be a potentially effective method for the treatment of $\mathrm{DN}$. Here, we seek to review the contribution of Nrf2/ARE pathway activation to $\mathrm{DN}$.

\section{Oxidative Stress and $D N$}

The nature of oxidative stress is the disproportionate generation of reactive oxygen species (ROS) and endogenous antioxidants. Low ROS level in body is crucial for survival and proliferation. High level of ROS leads to cellular apoptosis. Extremely high level of ROS gives rise to the damage of cellular macromolecules, including DNA [7], lipid [8], and protein [9]. It will cause mutations and followed by tissue injury or even necrotic cell death if those damages were not repaired [10]. 


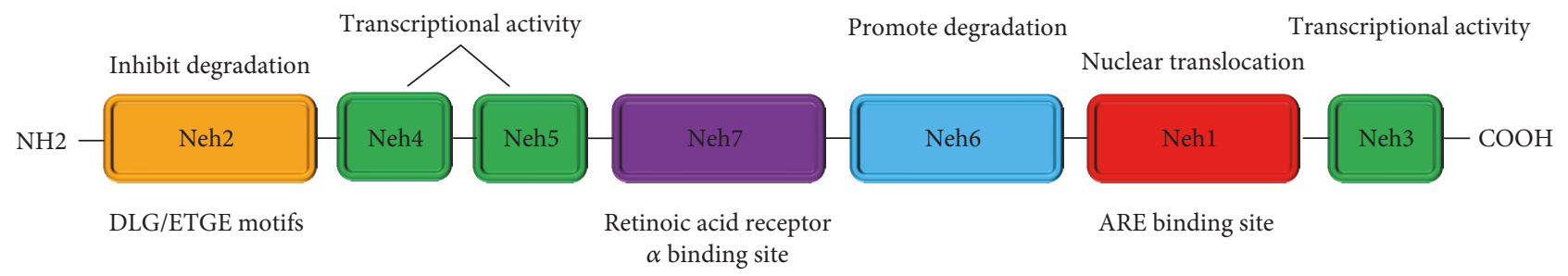

(a)

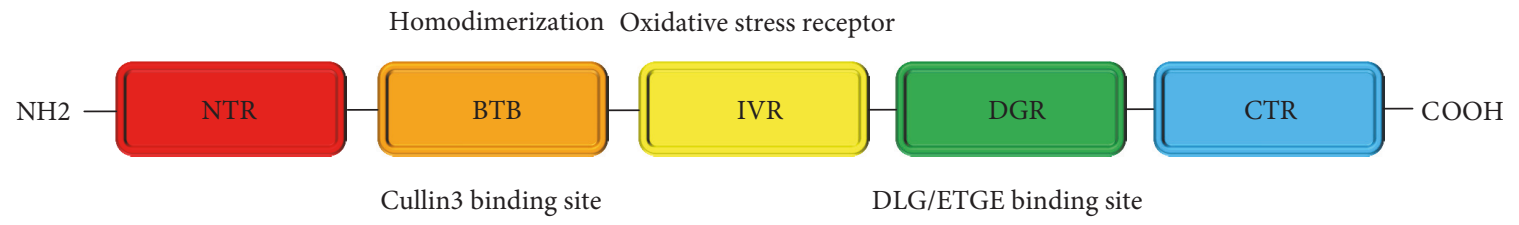

(b)

Figure 1: Molecular structure of Nrf2 (a) and Keap1 (b) proteins. (a) There are seven domains in the Nrf2 molecule, and a brief explanatory note for the main function of each domain was given. (b) There are five domains in the Keap1 molecule, and a brief explanatory note for the main function of each domain was given.

Under diabetes condition, oxidative stress is triggered through a variety of ways, such as advanced glycation endproduct accumulation and activation of polyol pathway, protein kinase $\mathrm{C}$ pathway, and renin angiotensin-aldosterone system. It is well accepted that oxidative stress takes part in the pathogenesis of DN. A large number of excellent reviews have shown that oxidative stress accelerates the progress of experimental DN $[4,11,12]$. For example, in type 1 diabetes rats, kidney expression of superoxide dismutase together with glutathione was obviously decreased, while restoring these two enzymes inhibited the progression of DN [13]. For type 2 diabetes rats, similarly, upregulation of malondialdehyde and downregulation of antioxidant enzymes, such as superoxide dismutase and glutathione, were observed in diabetes rat kidney. And, restoration of these enzymes halted hyperglycemia-induced oxidative stress and maintained renal function [14]. Moreover, it is not difficult to obtain similar evidence from clinical studies [15-17]. For example, in new published clinical trials, individuals who suffered from DN were enrolled. Kidney injury was attenuated accompanied by improving oxidative stress biomarkers (nitric oxide, glutathione, and malondialdehyde) after short-term supplementation of selenium or vitamin $\mathrm{E}[15,16]$. Taken together, antioxidative stress therapy might bring favorable outcomes to patients with DN.

\section{Oxidative Stress and Nrf2/ARE Pathway}

3.1. Components of Nrf2/ARE Pathway. Nrf2 is a smart transcription factor with a basic leucine zipper motif [18]. It has seven highly conserved Nrf2-ECH homology domains, Neh1 to Neh7 $[19,20]$. Neh1 domain includes a basic leucine zipper structure, which facilitates dimerization with small musculoaponeurotic fibrosarcoma (sMaf) protein and binding to ARE [21]. Besides, Neh1 also promotes the cytoplasmic-tonuclear translocation of Nrf2 [22]. Neh2 domain is highly conserved between species [23] and enables Nrf2 to combine with Kelch-like ECH-associated protein 1 (Keap1) [24, 25].
Additionally, the presences of lysine residues and a serine residue in Neh2 domain are involved in the suppression of proteasome-mediated Nrf2 degradation [26] and Nrf2Keap 1 complex structure modulation, respectively. The functions of Neh3-Neh6 domains are relatively simple. Briefly, Neh3-Neh5 domains are essential for Nrf2 transcriptional activity [27], and Neh6 domain is associated with Nrf2 degradation [28]. Neh7 domain, which has been identified recently, suppresses Nrf2 downstream gene expression through binding to the retinoic acid receptor $\alpha$ [29]. Nrf2 molecular structure is given in Figure 1(a).

Keap1 was first recognized in 1999 with the application of the Neh2 domain of Nrf2 [25]. The Keap1 molecules from different species are slightly different. The number of cysteine residues in the Keap1 molecule from mouse and human beings is 25 and 27, respectively. To be noticed, cysteine residues are sensors for Nrf2 activation [30]. Five domains have been discovered in the Keap1 molecule. They are NTR, BTB, IVR, DGR, and CTR [23]. The BTB domain is required for the homodimerization of Keap1 [31] and the interaction between Keap1 and Cullin3-Rbx1E3 ubiquitin ligase (Cul3E3-ligase) [32]. The cysteine-rich IVR domain is sensitive to oxidation [33]. Three important cysteine residues (Cys151, Cys273, and Cys288) were identified to be crucial for maintaining the structural integrity of Keap1 [34-36]. The DGR domain is where Keap1 binds to the Neh2 domain of Nrf2 [37]. The Keap1 molecular structure is given in Figure 1(b).

3.2. Working Model of Nrf2/ARE Pathway. Nrf2/ARE pathway plays a crucial role in cellular resistance to oxidative stress [5]. Under rest conditions, Keap1 interacts with Nrf2 to form a complex $[38,39]$. At this situation, Keap1 acts as an inhibitor of Nrf2. Moreover, this Nrf2 inhibitor can also interact with Cul3-E3-ligase, which mediates Nrf2 degradation in ubiquitin-proteasome system. After that, the transcription function of Nrf2 is repressed [40] (Figure 2(a)). During oxidative stress, Nrf2 is activated. By modifying the 


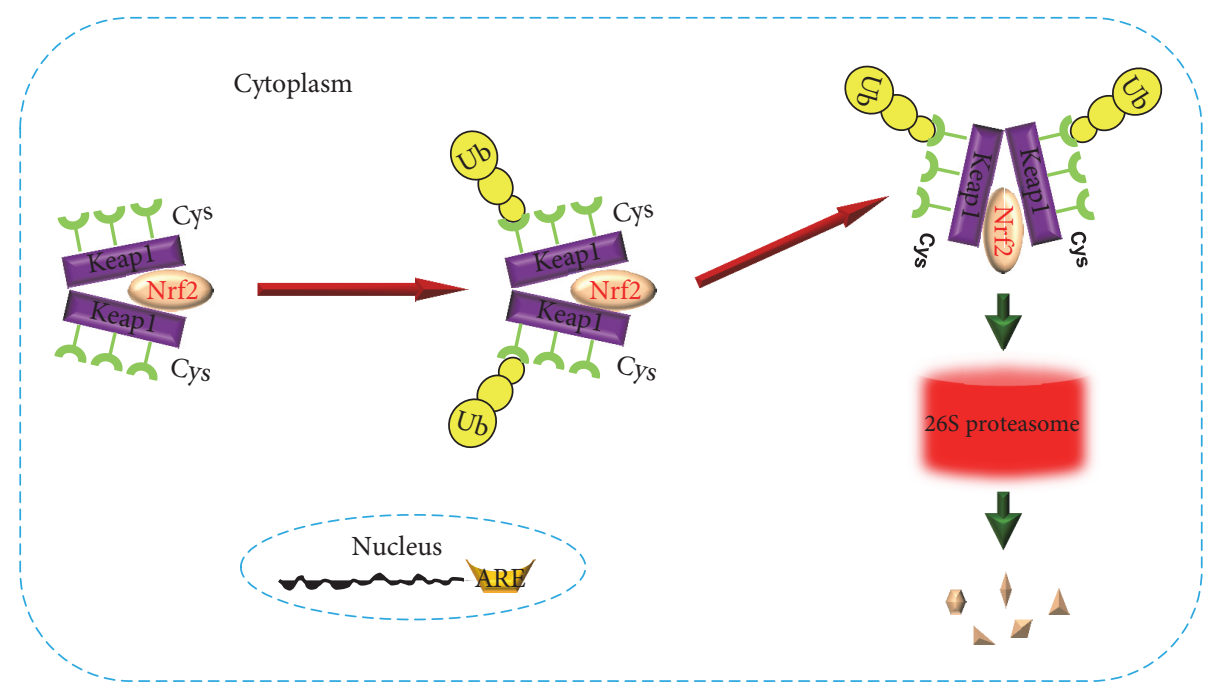

(a)

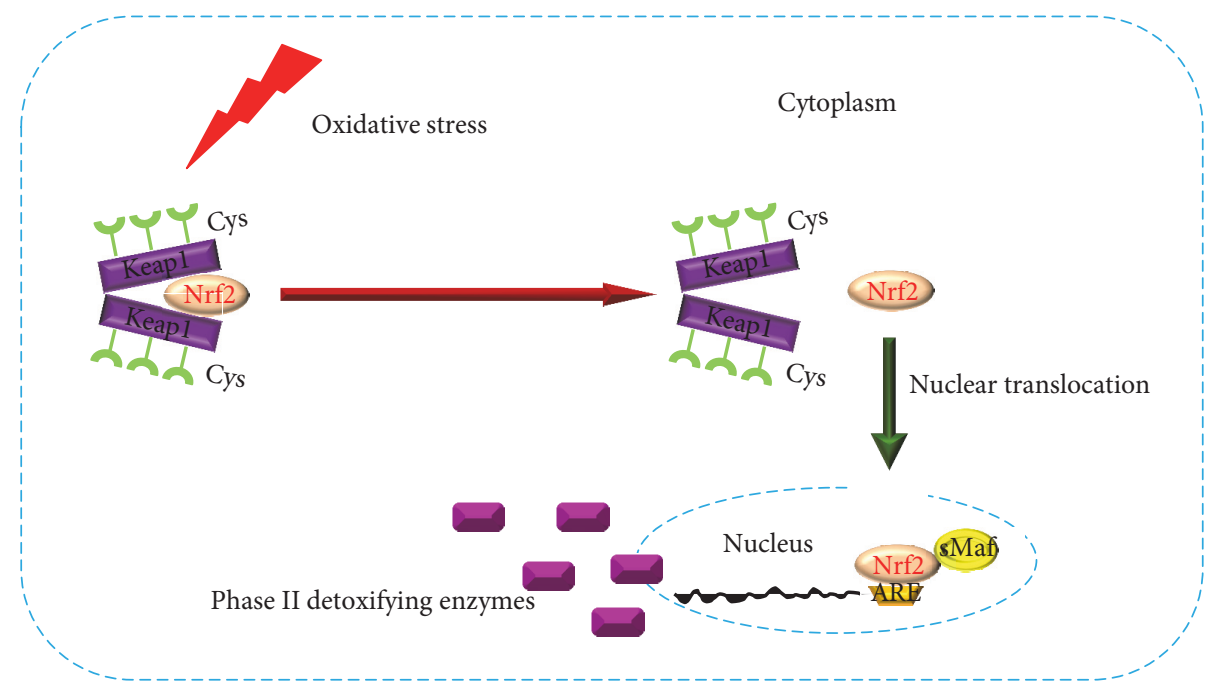

(b)

FIGURE 2: Working model of Nrf2/ARE pathway. (a) Working model of Nrf2/ARE pathway under rest conditions. (b) Working model of Nrf2/ARE pathway during oxidative stress.

three important cysteine residues of Keap1, conformational changes occur in the Nrf2/Keap1 complex [30, 35], leading to Nrf2 liberalization, followed by Nrf2 translocation. In the nucleus, Nrf2 binds to ARE with the help of sMaf protein [21]. Then, Nrf2 triggers the transcription of phase II detoxification enzymes and antioxidants, such as heme oxygenase1 and superoxide dismutase 1 [41-43] (Figure 2(b)).

3.3. Nrf2/ARE Pathway Regulation. As an executor, Nrf2/ ARE signaling pathway is regulated by complex mechanisms [44]. The regulation models include transcriptional level, translational level, and posttranslational level. To examine the mechanisms of Nrf2 transcriptional activation, Kwak et al. found that Nrf2 could autoregulate itself via a specific element of its own promoter [45]. Nowadays, microRNAs are thought to take part in the regulation of oxidative stress [46]. It was suggested that Nrf2 gene could be directly downregulated by miR-28 [47], miR-34a [48], and miR-144 [49].
Additionally, Nrf2 gene could be indirectly regulated by miR-200a-driven Keap1 gene downregulation [50]. Moreover, it is suggested that both DNA methylation [51, 52] and histone modification $[53,54]$ can regulate Nrf2/ARE pathway. Such information about the epigenetic regulation of Nrf2 and Keap1 was well summarized in a review article [55].

As we talked above, Nrf2 is degraded in ubiquitinproteasome system. This process keeps Nrf2 protein at a low level and maintains cellular redox homoeostasis by preventing transcription of undesired genes. Therefore, protein level of Nrf2 can be controlled by both regulation of ubiquitin ligases [56] and proteasome activity [57]. In addition to ubiquitin-proteasome system, other proteins can regulate Nrf2 by interacting with the Nrf2-Keap1 complex. For example, autophagy pathway inhibition leads to excessive p62 accumulation. By directly interacting with Keap1, p62 blots Keap1-mediated Nrf2 degradation [58]. 
Besides regulating transcription and translation, Nrf2 pathway can also be regulated after translation. For example, protein kinase $\mathrm{C}$ catalyzes Nrf2 phosphorylation at serine 40 residue, which is critical for promoting Nrf2 separation from Keap1 [59]. Interestingly, p66Shc which takes part in cellular stress response is transcriptionally regulated by Nrf2. However, p66Shc also controls the expression of several Nrf2 downstream genes, like $\mathrm{NAD}(\mathrm{P}) \mathrm{H}$ :quinone oxidoreductase 1 [60]. Taken together, all these signaling pathway regulation methods have the potential to be used for antioxidative stress strategies.

\section{Role of Nrf2/ARE Pathway in DN: Evidences in Basic Research}

The effects of Nrf2/ARE pathway activation on DN in different experimental models were well documented in the past ten years [61]. Sun et al. revealed proper time nodes of Nrf2 signaling pathway in different processes of $\mathrm{DN}$ in rats [62]. In addition, hyperglycemia-induced oxidative stress and accelerated renal injury were more serious in streptozotocin-treated Nrf2 knockout mice than those in wild-type controls [63-65], indicating a beneficial effect of Nrf2 on DN. With the expectation that Nrf2-targeted genes would be increased, Keap1 knockout and knockdown mice were generated. However, Keap1 knockout mice died early because of severe defects [66], and Keap1 knockdown mice show different impact effects on metabolic homeostasis [67-69]. The possible reasons for the discrepancy could be the component and content of the diet and the length of high-fat feeding. To be noticed, genetic and pharmacological activation of Nrf2 is constitutive and intermittent, respectively, and the levels of Nrf2 downstream genes in the genetically modified mice were higher than those induced by pharmacological Nrf2 inducers [70]. Moreover, aberrant Nrf2 activation causes unexpected side effects, which will be discussed at the end of this review. Therefore, either pharmacologically activating Nrf2 pathway or inhibiting Nrf2 degradation intermittently might be considered as potential strategies for treating DN.

Recently, a mount of Nrf2 activators have been applied to explore the therapeutic potential of Nrf2 in experimental DN models. In these studies, Nrf2 activators acted upon a series of targets via different mechanisms. The information of these articles was summarized and listed in Table 1 [57, 71-106].

4.1. Nrf2-Keap1 Complex Modulation. As a novel Nrf2 activation strategy, directly destroying Nrf2-Keap1 complex has been proved to be effective. For example, under diabetes condition, miR-29 was downregulated. Because miR-29 directly targeted to Keap1 mRNA, Nrf2 content was indirectly reduced [81]. Our previous study demonstrated that C66 (a novel curcumin analogue) ameliorated DN by miR200a-mediated Nrf2 activation [93]. This method of Nrf2 regulation by miR-200a was confirmed by another study from Wei et al. [107]. Taken together, miR-29 activator and miR-200a activator have the potential to be used in the treatment of DN.
Huang et al. claimed that, in HepG2 cells, PKC promoted Nrf2 phosphorylation at Ser-40. This modulation broke the Nrf2-Keap1 complex and promoted the division between Nrf2 and Keap1 [59]. Therefore, developing medicines inhibiting the interaction between Nrf2 and Keap1-Nrf2 will be a valuable topic.

4.2. Reduction of Nrf2 Degradation. The degradation of Nrf2 occurs in the proteasome system. Thus, suppressing the degradation of Nrf2 via inhibiting proteasome activity seems to be a reasonable strategy for DN. Studies from both other and our groups revealed that low dose of MG132, a proteasome inhibitor, had preventive and therapeutic effects on the development and progression of DN in rodents $[57,106]$.

In addition, minocycline which has been widely used in clinical research is beneficial to the stabilization of endogenous Nrf2 in the kidneys of $d b / d b$ mice, followed by the reduction of glomerular ROS generation. The underlying mechanism might be minocycline could reduce Nrf2 ubiquitination and then decrease its degradation. However, minocycline-mediated amelioration of $\mathrm{DN}$ disappeared in diabetic Nrf2 knockout mice [92].

4.3. Cytoplasm-to-Nuclear Shuttling of Nrf2. Under certain condition, Nrf2 shuttles from cytoplasm to nucleus. Nucleus accumulation of $\mathrm{Nrf} 2$ was proven to be effective against diabetes-induced kidney injury [94]. Using human renal tubular cells, our previous study claimed that Zinc increased the Nrf2 protein level in nucleus and upregulated the expression of Nrf2 downstream enzymes through promoting Akt/ GSK-3 $\beta$-mediated inhibition of Fyn, which is a Nrf2 nuclear exporter [98]. Following studies confirmed our viewpoint in type 1 diabetic rodents by using fenofibrate [95] and sulforaphane [96], respectively. Interestingly, it was suggested that sulforaphane mainly induced $\mathrm{Nrf} 2$ via modification of Keap1 Cys151 [36]. However, Shang et al. demonstrated that sulforaphane attenuated experimental DN partially through GSK-3 $\beta /$ Fyn/Nrf2 pathway [96]. This study provided another possible mechanism underlying the regulation of Nrf2 by sulforaphane. Additionally, Chen et al. found that connexin 43 might hinder the nuclear export of Nrf2 by inhibiting c-Src activity and then attenuate renal fibrosis in high glucose-treated glomerular mesangial cells [91]. All these Nrf2 activators promoted Nrf2 nucleus accumulation by blocking Nrf2 export.

Moreover, beneficial effects of facilitating the nuclear import of Nrf2 by other Nrf2 activators, such as hydrogen sulfide [100], hepatocyte growth factor [103], and tertbutylhydroquinone [105], were proved in many experimental DN models, indicating the importance of the regulation of cytoplasm-to-nuclear shuttling of Nrf2 in the treatment of DN.

4.4. Other Underlying Mechanisms for Nrf2 Activation. In a recent study, streptozotocin-treated $\mathrm{Nrf} 2$ knockout mice and wild-type controls were administrated with or without sodium butyrate for twenty weeks. Data showed that Nrf2 played a key role in the process of sodium butyrate protection against DN. Additionally, sodium butyrate might upregulate 
TABLe 1: Beneficial effect of Nrf2 activators on experimental DN.

\begin{tabular}{|c|c|c|c|}
\hline Nrf2 activator & DN model & Results & Ref. \\
\hline Sulforaphane & $\begin{array}{l}\text { T1DM mice; human renal } \\
\text { tubular cells }\end{array}$ & $\begin{array}{l}\text { Sulforaphane alleviates renal inflammation, oxidative stress, fibrosis, and } \\
\text { dysfunction in DN mice via activation of Nrf2/ARE pathway (HO-1, } \\
\text { SOD1, etc.); beneficial effects disappeared when Nrf2 siRNA was applied }\end{array}$ & {$[85]$} \\
\hline Sulforaphane & $\begin{array}{l}\text { T1DM mice; human renal } \\
\text { mesangial cells }\end{array}$ & $\begin{array}{l}\text { Sulforaphane normalizes diabetes-induced kidney oxidative damage, } \\
\text { fibrosis, and apoptosis, which is mediated by Nrf2/ARE pathway (NQO1, } \\
\text { rGCS, and MRP2) activation; beneficial effects disappeared in Nrf2 } \\
\text { knockout mice }\end{array}$ & {$[86]$} \\
\hline Sulforaphane & T2DM mice & $\begin{array}{l}\text { Sulforaphane improves kidney oxidative damage, inflammation, and } \\
\text { fibrosis in diabetic mice, accompanied by increasing kidney Nrf2 and its } \\
\text { downstream gene metallothionein; beneficial effects disappeared in Nrf2 } \\
\text { knockout mice }\end{array}$ & [89] \\
\hline Sulforaphane & T1DM rats & $\begin{array}{l}\text { Sulforaphane ameliorates DN through GSK } 3 \beta / \mathrm{Fyn} / \mathrm{Nrf} 2 \text { signaling pathway } \\
\text { (prevents nuclear export of Nrf2) }\end{array}$ & [96] \\
\hline $\begin{array}{l}\text { Resveratrol and } \\
\text { rosuvastatin }\end{array}$ & T1DM mice & $\begin{array}{l}\text { Resveratrol combined with rosuvastatin treatment normalizes the TGF- } \beta 1 \text {, } \\
\text { FN, and NF- } \kappa \mathrm{B} / \mathrm{p} 65 \text { and restores Nrf } 2 \text { in renal tissues of diabetic rats }\end{array}$ & {$[74]$} \\
\hline Resveratrol & T1DM rats; rat mesangial cells & $\begin{array}{c}\text { Resveratrol reduces albuminuria and mesangial matrix expansion in DN } \\
\text { rats and attenuates mesangial cell proliferation, which is associated with } \\
\text { upregulation of Nrf2 and glutathione S-transferases } \mathrm{Mu}\end{array}$ & {$[84]$} \\
\hline Resveratrol & T1DM rats & $\begin{array}{l}\text { Resveratrol protects against DN by alleviating oxidative damage and } \\
\text { inflammation through Nrf2/ARE pathway (SOD, CAT, etc.) }\end{array}$ & [87] \\
\hline Resveratrol & $\begin{array}{l}\text { Rat primary glomerular } \\
\text { mesangial cells }\end{array}$ & $\begin{array}{l}\text { Resveratrol inhibits AGE-induced FN and TGF- } \beta 1 \text { in glomerular } \\
\text { mesangial cells through Sirt1/Nrf2 signaling pathway activation }\end{array}$ & [101] \\
\hline $\begin{array}{l}\text { Polydatin (resveratrol } \\
\text { analogue) }\end{array}$ & $\begin{array}{l}\text { T1DM rats; rat glomerular } \\
\text { mesangial cells }\end{array}$ & $\begin{array}{l}\text { Polydatin inhibits AGE-induced FN and TGF- } \beta 1 \text { in glomerular mesangial } \\
\text { cells is associated with activation of Sirt1/Nrf2 pathway }\end{array}$ & {$[97]$} \\
\hline Curcumin & T2DM rats & $\begin{array}{l}\text { Curcumin ameliorates albuminuria, kidney pathophysiologic changes, and } \\
\text { urinary MDA, accompanied by increasing Nrf2, HO-1, and urinary SOD }\end{array}$ & {$[78]$} \\
\hline Curcumin & $\begin{array}{l}\text { Rat kidney tubular epithelial } \\
\text { cells }\end{array}$ & $\begin{array}{l}\text { Curcumin protects renal tubular cells from high glucose-induced EMT } \\
\text { through upregulating Nrf2 and HO-1; beneficial effects disappeared when } \\
\text { Nrf2 siRNA was applied }\end{array}$ & {$[80]$} \\
\hline $\begin{array}{l}\text { C66 (curcumin } \\
\text { analogue) }\end{array}$ & T1DM mice & $\begin{array}{c}\text { C66 protects against DN by upregulating Nrf2 via both increasing } \\
\text { miR-200a and inhibiting miR-21; beneficial effects were partially } \\
\text { abolished in Nrf2 knockout mice }\end{array}$ & [93] \\
\hline Zinc & Human renal tubular cells & $\begin{array}{c}\text { Zn sensitizes Nrf2 by facilitating Akt-associated Fyn inhibition } \\
\text { (prevents Nrf2 nuclear export) and thus alleviates kidney oxidative } \\
\text { and inflammatory damage and fibrosis }\end{array}$ & {$[98]$} \\
\hline Zinc & $\begin{array}{l}\text { Rat kidney tubular } \\
\text { epithelial cells }\end{array}$ & $\begin{array}{l}\text { Zinc ameliorates high glucose-mediated apoptosis in rat kidney } \\
\text { tubular cells through Akt/ERK/Nrf2 signaling pathway activation } \\
\text { (promotes Nrf2 accumulation in nuclear) }\end{array}$ & [99] \\
\hline MG132 & $\begin{array}{l}\text { T1DM mice; human renal } \\
\text { tubular cells }\end{array}$ & $\begin{array}{c}\text { MG132 sensitizes Nrf2 by inhibiting proteasome activity and thus } \\
\text { attenuates hyperglycemia-induced kidney oxidative and inflammatory } \\
\text { damage, fibrosis, and eventual dysfunction; beneficial effects } \\
\text { disappeared when Nrf2 siRNA was applied }\end{array}$ & {$[57]$} \\
\hline MG132 & T1DM rats & $\begin{array}{l}\text { Low dose of MG132 prevents diabetes-induced kidney damage by } \\
\text { Nrf2/ARE pathway activation }\end{array}$ & [106] \\
\hline Rutin & $\begin{array}{l}\text { Human renal glomerular } \\
\text { endothelial cells }\end{array}$ & $\begin{array}{l}\text { Rutin significantly prevents hyperglycemia-induced glomerular endothelial } \\
\text { barrier disruption by decreasing ROS through the activation of Nrf2 }\end{array}$ & {$[71]$} \\
\hline Berberine & $\begin{array}{l}\text { T1DM mice; rat renal tubular } \\
\text { epithelial cells }\end{array}$ & $\begin{array}{c}\text { Berberine ameliorates high glucose-induced EMT and oxidative stress } \\
\text { by Nrf2/ARE pathway (HO-1 and NQO1) activation and TGF- } \beta \text { /EMT } \\
\text { pathway inhibition; beneficial effects disappeared when Nrf2 siRNA } \\
\text { was applied }\end{array}$ & {$[72]$} \\
\hline $\begin{array}{l}\text { Casein kinase } 2 \\
\text { interacting protein-1 }\end{array}$ & Rat glomerular mesangial cells & $\begin{array}{c}\text { Casein kinase } 2 \text { interacting protein-1 downregulates ICAM-1 and FN by } \\
\text { Nrf2/ARE pathway (SOD1 and HO-1) activation }\end{array}$ & {$[73]$} \\
\hline Salvianolic acid A & T1DM mice & $\begin{array}{l}\text { Salvianolic acid A protects DN via Nrf2/ARE pathway } \\
\text { (HO-1, NQO1, and GPx-1) }\end{array}$ & {$[75]$} \\
\hline
\end{tabular}


TABLE 1: Continued.

\begin{tabular}{|c|c|c|c|}
\hline Nrf2 activator & DN model & Results & Ref. \\
\hline Sinomenine & $\begin{array}{l}\text { Human renal glomerular } \\
\text { endothelial cells }\end{array}$ & $\begin{array}{c}\text { Sinomenine reduces ROS level and exerts renal protective effect by } \\
\text { activating Nrf2 in high glucose-treated human renal glomerular } \\
\text { endothelial cells }\end{array}$ & {$[76]$} \\
\hline $\begin{array}{l}\text { Momordica charantia } \\
\text { polysaccharides }\end{array}$ & T1DM rats & $\begin{array}{c}\text { Momordica charantia polysaccharides attenuate type } 1 \mathrm{DN} \text { in rats by } \\
\text { upregulating Nrf2, CAT, GSH, and SOD }\end{array}$ & [77] \\
\hline Digitoflavone & T1DM mice & $\begin{array}{l}\text { Digitoflavone minimizes pathological changes, decreases oxidative and } \\
\text { inflammatory damage as well as fibrosis in DN mice, which is mediated by } \\
\text { Nrf2 pathway (GCLC and HO-1) activation; beneficial effects disappeared } \\
\text { in Nrf2 knockout mice }\end{array}$ & {$[78]$} \\
\hline $\begin{array}{l}\text { Thrombomodulin } \\
\text { domain } 1\end{array}$ & T2DM mice & $\begin{array}{l}\text { Thrombomodulin domain } 1 \text { improves } \mathrm{DN} \text { by suppressing inflammation, } \\
\text { activating the Nrf2 pathway, and inhibiting apoptosis in the mouse kidney }\end{array}$ & {$[82]$} \\
\hline Maxacalcitol & T2DM mice & $\begin{array}{c}\text { Maxacalcitol alleviates DN by suppressing kidney oxidative and } \\
\text { inflammatory damage as well as fibrosis, which is mediated by Nrf2 } \\
\text { pathway (GCLC and HO-1) activation }\end{array}$ & {$[83]$} \\
\hline 4-Phenylbutyric acid & T1DM rats & $\begin{array}{l}\text { Treatment with 4-phenylbutyric acid attenuates oxidative damage in DN } \\
\text { rats via Nrf2 facilitation }\end{array}$ & {$[88]$} \\
\hline Sodium butyrate & T1DM mice & $\begin{array}{l}\text { Sodium butyrate protects against } \mathrm{DN} \text { through } \mathrm{Nrf} 2 \text { upregulation, which is } \\
\text { mediated by suppressing HDAC function; beneficial effects disappeared in } \\
\text { Nrf2 knockout mice }\end{array}$ & {$[90]$} \\
\hline Connexin 43 & $\begin{array}{l}\text { Primary glomerular mesangial } \\
\text { cells; type } 2 \text { diabetic mice }\end{array}$ & $\begin{array}{c}\text { Connexin } 43 \text { activates Nrf2/ARE pathway by means of inhibiting c-Src } \\
\text { activity to hinder the nuclear export of Nrf2 and then downregulates FN, } \\
\text { ICAM-1, and TGF- } \beta 1 \text { expression and ultimately attenuates renal fibrosis in } \\
\text { diabetic mice }\end{array}$ & [91] \\
\hline Minocycline & $\begin{array}{l}\text { T1DM/T2DM mice; } \\
\text { human/mouse podocytes }\end{array}$ & $\begin{array}{l}\text { Minocycline stabilizes endogenous Nrf2 by reducing its ubiquitination and } \\
\text { reduces markers of oxidative damage, thus alleviated DN; beneficial effects } \\
\text { disappeared in Nrf2 knockout mice }\end{array}$ & [92] \\
\hline $\begin{array}{l}\text { Mycophenolate } \\
\text { mofetil }\end{array}$ & T1DM rats & $\begin{array}{l}\text { Mycophenolate mofetil attenuates DN at least in part by upregulating Nrf2 } \\
\text { pathway (increases the nuclear accumulation of Nrf2) }\end{array}$ & {$[94]$} \\
\hline Fenofibrate & T1DM mice & $\begin{array}{l}\text { Fenofibrate attenuates DN via increasing FGF21 and activating } \\
\text { Akt/GSK-3 } \beta / \text { Fyn/Nrf2 pathway (prevents Nrf2 nuclear export) }\end{array}$ & [95] \\
\hline Hydrogen sulfide & $\begin{array}{l}\text { T1DM rats; rat glomerular } \\
\text { mesangial cells }\end{array}$ & $\begin{array}{l}\text { Hydrogen sulfide alleviates DN by suppressing oxidative stress } \\
\text { (promotes Nrf2 accumulation in nuclear), inflammation, and } \\
\text { renin-angiotensin system activity, as well as by reducing mesangial } \\
\text { cell proliferation }\end{array}$ & {$[100]$} \\
\hline Low-dose radiation & T1DM mice & $\begin{array}{c}\text { Prevention of low-dose radiation against } \mathrm{DN} \text { is associated with Akt } \\
\text { phosphorylation and Nrf2 upregulation }\end{array}$ & [102] \\
\hline $\begin{array}{l}\text { Hepatocyte growth } \\
\text { factor }\end{array}$ & Rat mesangial cells & $\begin{array}{l}\text { Hepatocyte growth factor ameliorates high glucose-induced oxidative } \\
\text { damage in rat mesangial cells by upregulating 8-nitro-cGMP production, } \\
\text { accompanied by nuclear accumulation of Nrf2 }\end{array}$ & [103] \\
\hline Telmisartan & T2DM mice & $\begin{array}{l}\text { Telmisartan inhibits NAD }(\mathrm{P}) \mathrm{H} \text { oxidase and upregulates Nrf2 and SOD, } \\
\text { leading to the attenuation of diabetes-induced renal damage }\end{array}$ & [104] \\
\hline $\begin{array}{l}\text { tert- } \\
\text { butylhydroquinone }\end{array}$ & T1DM mice & $\begin{array}{l}\text { tert-butylhydroquinone reduces renal damage through nuclear } \\
\text { accumulation of Nrf } 2 \text { as well as its target genes in type } 1 \text { diabetic mice }\end{array}$ & [105] \\
\hline
\end{tabular}

Nrf2 at the transcriptional level possibly by inhibiting histone deacetylase activity [90]. As a NAD-dependent histone deacetylase in the nucleus, Sirt1 takes part in many biological processes [108] through working on a battery of transcription factors, including Nrf2 [109-111]. Studies revealed that both resveratrol [101] and its analogue (polydatin) [97] activated Nrf2/ARE pathway through upregulating Sirt1 in glomerular mesangial cells and attenuated high glucose caused fibrosis.

Moreover, Nrf2-dependent beneficial effects on the prevention of $\mathrm{DN}$ were observed in low dose of radiationtreated mice [102] and high glucose-treated NRK-52E cells
[99], respectively. Activation of Nrf2 in these two studies was reported to be responsible to Akt activation; however, whether Fyn was involved in this process was not mentioned $[99,102]$.

Oxidative stress aggrieves all kinds of kidney resident cells, including epithelium (podocyte), endothelium, glomerular mesangial cell, and tubular cell. According to Table 1, available evidences support that activation of Nrf2/ARE pathway not only attenuates high glucose-induced podocyte $[82,92,112,113]$, endothelium $[71,76]$, and mesangial cell $[73,86,91,97,101,103,105,107]$ injury in glomeruli but also alleviates renal tubular cell $[72,80,81,98,99]$ damage. In 
addition, sulforaphane $[85,86,89,96]$ and resveratrol $[74,84$, $87,97,101]$ are the most well-studied ones among those Nrf2 activators. Besides, curcumin and its analogues (C66) were also introduced in three studies $[78,80,93]$ and have emerged to be a potential therapeutic choice, which will be discussed later in this review.

Taken together, breaking the Nrf2-Keap1 complex, blocking Nrf2 degradation, and promoting Nrf2 cytoplasmic-tonuclear translocation are valuable strategies to increase antioxidant generation. These basic evidences provide us with new ideas for the treatment of oxidative stress-associated kidney injury under diabetes condition.

\section{Role of Nrf2/ARE Pathway in DN: Evidences in Clinical Research}

Beneficial effects of Nrf2/ARE pathway activation on DN can be observed in not only basic researches but also clinical researches. Additionally, the relationship of genetic variants of Nrf2 (rs2364723, rs10497511, rs1962142, and rs6726395) and diabetes complications in Han descents of Northeast China has been confirmed recently by our group [114]. Moreover, dysregulation of Nrf2 signaling was also observed in human diabetes kidney [64]. Thus, Nrf2 activators began to be used in patients with $\mathrm{DN}$ in clinical trials.

The most well-studied promising candidate Nrf2 activator is bardoxolone methyl (BM), which has been used not only for cancer [115] but also for many other oxidative stress and inflammation-involved chronic diseases [116]. $\mathrm{BM}$ was first introduced to clinicians because it possesses anticancer effects. When treating patients who suffered from malignant diseases, the investigators surprisingly found that BM could raise estimated GRF (eGFR), accompanied by increasing NQO1 mRNA in peripheral blood mononuclear cells. Interestingly, these improvements were more likely to be observed in a subset of patients with CKD $[117,118]$. Based on these observations, this multifunctional medicine was thought to ameliorate renal damage in type 2 diabetes patients.

With the encouraging idea, BM was further studied in a phase 2a clinical trial to evaluate its renoprotective efficacy and safety [119]. In this multicenter clinical trial, shortterm (8 weeks) effects of BM on kidney function was evaluated in type 2 diabetes patients and moderate to severe CKD (baseline serum creatinine level ranged from 1.3 to $3.0 \mathrm{mg} / \mathrm{dl})$. All enrolled patients were administrated with $25 \mathrm{mg}$ BM for 4 weeks and $75 \mathrm{mg}$ BM for next 4 weeks. Data showed that the administration of BM obviously increased eGFR and creatinine clearance while decreased serum creatinine and blood urea nitrogen. These results seemed very optimistic; however, two major limitations in this study should not be ignored. First, this was a self-control study and a placebo control group was needed to obtain a more convincing result. Second, the treatment course was not long enough to observe side effects.

Attempting to further verify the beneficial effects of BM in patients who suffered from diabetes and CKD, the BEAM study with a larger sample size was conducted [120]. To overcome the limitations in the previous phase 2 a clinical trial,
227 patients who suffered from diabetes mellitus and CKD were enrolled in the BEAM study. Participants were administrated with either placebo or different doses $(25,75$ or $150 \mathrm{mg} /$ day) of BM for 52 weeks. Data showed that BM ameliorated eGFR, which persisted during the 52-week treatment period. Moreover, adverse events reported in the BEAM study were moderate and manageable.

After obtaining these exciting results, the BEACON study was performed in June 2011 [121]. The purpose of this study was further confirming the beneficial effects of BM on safely reducing renal and cardiac morbidity and mortality among patients who suffered from diabetes mellitus and CKD. More than two thousands patients who suffered from type 2 diabetes mellitus and stage 4 CKD were recruited and randomly administrated with either placebo or BM $(20 \mathrm{mg} /$ day $)$ for 52 weeks. However, the BEACON study was stopped prematurely in October 2012 due to safety concerns about considerable adverse events as well as high mortality rates. Heart failure events (hospitalization or death) occurred in 96 from 1088 patients and 55 from 1097 patients in the BM group and placebo group, respectively. Moreover, composite outcome events (including nonfatal stroke and myocardial infarction, hospitalization because of heart failure, and death because of cardiovascular diseases) occurred in 139 from 1088 patients and 86 from 1097 patients in the BM group and placebo group, respectively. Compared to the placebo group, although eGFR was improved, urinary protein level and blood pressure were also obviously increased in the BM group during the study period.

The main reason for the termination of the BEACON study was high rates of heart failure, and many occurred early after BM initiation. Analyses aiming to find the reasons for heart failure events in the BEACON study were conducted $[122,123]$. Chin et al. claimed that both high B-type natriuretic peptide level and heart failure-caused hospitalization before were risk factors of heart failure [122]. Another mechanism underlying cardiovascular events in the BEACON study was also revealed by Chin et al. It was suggested that BM might pharmacologically lead to acute water-sodium retention and hypertension by modulating the endothelin pathway [123]. Besides heart failure events, hypertension was also more likely to happen in patients from the BM group than from the placebo group. There were two possible reasons to explain this phenomenon. First, endothelin pathway regulation by BM leads to sodium and volume retention as we described above. Second, by binding to the promoter of intrarenal angiotensinogen gene, Nrf2 stimulates its expression and then activates the renin-angiotensin system [124]. Therefore, BM might lead to hypertension by both sodium and volume retention and renin-angiotensin system activation.

In the BEACON study, investigators did observed elevated eGFR in the BM group. This phenomenon was possibly due to a similar structure between BM and cyclopentenone prostaglandins, which can cause renal vasodilatation. To be noticed, eGFR was calculated by serum creatinine in the BEAM study and muscle mass will influence the level of serum creatinine $[125,126]$. Compared to those in the placebo group, the degree of weight loss and muscle wasting in 
the BM group was higher, which might cause an overestimation of eGFR in the BM group [127].

Although some adverse events occurred in BM-treated patients, it cannot stop us from exploring new medicines for the treatment of DN. Different to BM, curcumin was proven to be effective in a $\mathrm{DN}$ experiment model [78, 80, 93]. In a recent clinical trial with small sample size, 14 patients with diabetic kidney disease were given curcumin $(500 \mathrm{mg} /$ day) for 2-4 weeks. It was claimed that short-term curcumin intervention attenuated kidney damage partially by activating Nrf2 pathway [128], which enhanced our confidence.

\section{Other Mechanisms of Nrf2 in the Treatment of DN}

6.1. Effects of Nrf2 Activation on Anti-Inflammation. Besides having an antioxidant property, Nrf2 was proven to alleviate inflammation, which is also involved in the progression of DN. Alleviation of kidney damages accompanied by downregulation of inflammatory cytokines (monocyte chemotactic protein-1, intercellular cell adhesion molecule-1) was observed in digitoflavone-treated wild-type diabetic mice instead of Nrf2 knockout diabetic mice [79]. However, the mechanism under which Nrf2 regulated these two proinflammatory mediators was not mentioned. Another study revealed direct evidence of inflammation suppression by Nrf2. Kobayashi et al. demonstrated that Nrf2 interfered with transcriptional upregulation of IL- 6 and IL- 1 b by binding to these two genes and inhibiting RNA polymerase II recruitment [129].

6.2. Effects of Nrf2 Activation on Antifibrosis. Fibrosis is an ultimate pathway in the pathogenesis of DN, and TGF- $\beta 1$ advances kidney fibrosis. It was suggested that Nrf2 ameliorated $\mathrm{DN}$ by transcriptional repression of TGF- $\beta 1$ directly. Gao et al. found that Nrf2 inhibited TGF- $\beta 1$ through binding to the specific region in TGF- $\beta 1$ promoter with the help of c-Jun as well as SP1 [130]. This study provided a novel clue for DN prevention and intervention.

\section{Side Effects of Nrf2 Activation}

Considerable evidence showed beneficial effects of Nrf2 on DN. However, side effects of this molecule should also be noticed. Zoja et al. treated type 2 diabetic rats with a synthetic triterpenoid analogue of BM (RTA405). They demonstrated that RTA405 elevated mortality, aggravated proteinuria, dyslipidemia, kidney function, and liver function [131]. These findings indicated the toxicity of this molecule. In addition, by using another BM analogue (dh404), the deleterious and salutary actions of Nrf2 activation in the treatment of DN were reported to be dose-dependent. Low dose of dh404 might alleviate kidney damage, while high dose of dh404 might lead to deterioration of the kidney function $[132,133]$. Therefore, consideration of the appropriate dose is necessary when applying the BM analogues.

Dural roles of Nrf2 in cancer have also been reported $[134,135]$. Some studies suggested that aberrant Nrf2 activation was correlated with cancer progression. For example, one important mechanism of hereditary leiomyomatosis and renal cell carcinoma is fumarate hydratase inactivationinduced fumarate accumulation. Sustained fumarate accumulation leads to aberrant $\mathrm{Nrf} 2$ activation and then gives rise to fatal consequences [136]. Nrf2 contributes to cancer cell survival not only by upregulating the expression of $\mathrm{Bcl}-\mathrm{xl}$ and $\mathrm{Bcl}-2$ to inhibit apoptosis [137] but also by raising the rate of glycolysis to promote cell proliferation [138].

Intrarenal renin-angiotensin system causes blood pressure elevation and kidney damage. Another side effect of Nrf2 activation that should be noticed is that Nrf2 can activate the renin-angiotensin system directly [139]. For example, Abdo et al. found that overexpression of Nrf2 promoted angiotensinogen gene transcription in high glucose-treated renal proximal tubule cells. Moreover, application of Nrf2 siRNA reduced angiotensinogen $\mathrm{mRNA}$ and protein expression [124].

\section{Conclusions}

In summary, oxidative stress is an important pathogenesis of DN. As the center of the body antioxidant system, Nrf2/ARE pathway is of great value in the treatment of DN. Modulating Nrf2/ARE pathway through different mechanisms provides new approaches for future clinical research studying the treatment of DN. It was worth noting that there was no evidence to support the application of BM in animal DN before the BEACON study. Therefore, before designing a new clinical trial, investigators should make sure that preliminary studies have been done and should not ignore any negative outcome. Moreover, in order to avoid the occurrence of a large number of serious adverse events, possible side effects of Nrf2 activation need to be monitored during the period of trial conduction.

\section{Ethical Approval}

This manuscript is a review study and does not have a concern with ethical problems.

\section{Conflicts of Interest}

The authors declare that they have no competing interests.

\section{Authors' Contributions}

Wenpeng Cui, Bing Du, and Ping Luo designed and wrote this manuscript. Xu Min and Xiaohong Xu revised this manuscript. All of the authors read and approved the final manuscript.

\section{Acknowledgments}

This study was supported in part by the National Natural Science Foundation of China (no. 81200525), Jilin Province Science and Technology Development Program (funded Projects no. 20150520034JH and no. 20160414014GH), Jilin Province Scientific Research Program (funded Project no. 2016446), and Norman Bethune Program of Jilin University (no. 2015214). The authors would like to express their gratitude to all the physicians participating in this work. 


\section{References}

[1] M. Haneda, K. Utsunomiya, D. Koya et al., "A new classification of diabetic nephropathy 2014: a report from Joint Committee on Diabetic Nephropathy," Clinical and Experimental Nephrology, vol. 19, no. 1, pp. 1-5, 2015.

[2] H. Gallagher and R. J. Suckling, "Diabetic nephropathy: where are we on the journey from pathophysiology to treatment?" Diabetes, Obesity \& Metabolism, vol. 18, no. 7, pp. 641-647, 2016.

[3] A. G. Miranda-Diaz, L. Pazarin-Villasenor, F. G. YanowskyEscatell, and J. Andrade-Sierra, "Oxidative stress in diabetic nephropathy with early chronic kidney disease," Journal of Diabetes Research, vol. 2016 no. 6, p. 7047238, 2016.

[4] M. K. Arora and U. K. Singh, "Oxidative stress: meeting multiple targets in pathogenesis of diabetic nephropathy," Current Drug Targets, vol. 15, no. 5, pp. 531-538, 2014.

[5] W. Cui, Y. Bai, P. Luo, L. Miao, and L. Cai, "Preventive and therapeutic effects of MG132 by activating Nrf2-ARE signaling pathway on oxidative stress-induced cardiovascular and renal injury," Oxidative Medicine and Cellular Longevity, vol. 2013 no. 3, p. 306073, 2013.

[6] J. A. Johnson, D. A. Johnson, A. D. Kraft et al., "The Nrf2ARE pathway: an indicator and modulator of oxidative stress in neurodegeneration," Annals of the new York Academy of Sciences, vol. 1147 no. 12, pp. 61-69, 2008.

[7] Y. Kaya, A. Cebi, N. Soylemez, H. Demir, H. H. Alp, and E. Bakan, "Correlations between oxidative DNA damage, oxidative stress and coenzyme Q10 in patients with coronary artery disease," International Journal of Medical Sciences, vol. 9, no. 8, pp. 621-626, 2012.

[8] N. J. Pillon, M. L. Croze, R. E. Vella, L. Soulere, M. Lagarde, and C. O. Soulage, "The lipid peroxidation by-product 4hydroxy-2-nonenal (4-HNE) induces insulin resistance in skeletal muscle through both carbonyl and oxidative stress," Endocrinology, vol. 153, no. 5, pp. 2099-2111, 2012.

[9] P. Piomboni, A. Stendardi, L. Gambera et al., "Protein modification as oxidative stress marker in normal and pathological human seminal plasma," Redox Report, vol. 17, no. 5, pp. 227-232, 2012.

[10] D. A. Abed, M. Goldstein, H. Albanyan, H. Jin, and L. Hu, "Discovery of direct inhibitors of Keap1-Nrf2 proteinprotein interaction as potential therapeutic and preventive agents," Acta Pharmaceutica Sinica B, vol. 5, no. 4, pp. 285299, 2015.

[11] N. Kashihara, Y. Haruna, V. K. Kondeti, and Y. S. Kanwar, "Oxidative stress in diabetic nephropathy," Current Medicinal Chemistry, vol. 17, no. 34, pp. 4256-4269, 2010.

[12] N. Vasavada and R. Agarwal, "Role of oxidative stress in diabetic nephropathy," Advances in Chronic Kidney Disease, vol. 12, no. 2, pp. 146-154, 2005.

[13] L. Kishore, N. Kaur, and R. Singh, "Renoprotective effect of Bacopa monnieri via inhibition of advanced glycation end products and oxidative stress in STZ-nicotinamide-induced diabetic nephropathy," Renal Failure, vol. 38, no. 9, pp. 1528-1544, 2016.

[14] S. Ahmed, N. Mundhe, M. Borgohain et al., "Diosmin modulates the NF-kB signal transduction pathways and downregulation of various oxidative stress markers in alloxan-induced diabetic nephropathy," Inflammation, vol. 39, no. 5, pp. 1783-1797, 2016.
[15] F. Bahmani, M. Kia, A. Soleimani, A. A. Mohammadi, and Z. Asemi, "The effects of selenium supplementation on biomarkers of inflammation and oxidative stress in patients with diabetic nephropathy: a randomised, double-blind, placebo-controlled trial," The British Journal of Nutrition, vol. 116, no. 7, pp. 1222-1228, 2016.

[16] P. G. Khatami, A. Soleimani, N. Sharifi, E. Aghadavod, and Z. Asemi, "The effects of high-dose vitamin E supplementation on biomarkers of kidney injury, inflammation, and oxidative stress in patients with diabetic nephropathy: a randomized, double-blind, placebo-controlled trial," Journal of Clinical Lipidology, vol. 10, no. 4, pp. 922-929, 2016.

[17] S. Ogawa, T. Mori, K. Nako, T. Kato, K. Takeuchi, and S. Ito, "Angiotensin II type 1 receptor blockers reduce urinary oxidative stress markers in hypertensive diabetic nephropathy," Hypertension, vol. 47, no. 4, pp. 699-705, 2006.

[18] P. Moi, K. Chan, I. Asunis, A. Cao, and Y. W. Kan, "Isolation of NF-E2-related factor 2 (Nrf2), a NF-E2-like basic leucine zipper transcriptional activator that binds to the tandem NF-E2/AP1 repeat of the beta-globin locus control region," Proceedings of the National Academy of Sciences of the United States of America, vol. 91, no. 21, pp. 9926-9930, 1994.

[19] K. Itoh, J. Mimura, and M. Yamamoto, "Discovery of the negative regulator of Nrf2, Keap1: a historical overview," Antioxidants \& Redox Signaling, vol. 13, no. 11, pp. 16651678, 2010.

[20] Y. S. Keum and B. Y. Choi, "Molecular and chemical regulation of the Keap1-Nrf2 signaling pathway," Molecules, vol. 19, no. 7, pp. 10074-10089, 2014.

[21] K. Itoh, T. Chiba, S. Takahashi et al., "An Nrf2/small Maf heterodimer mediates the induction of phase II detoxifying enzyme genes through antioxidant response elements," Biochemical and Biophysical Research Communications, vol. 236, no. 2, pp. 313-322, 1997.

[22] A. K. Jain, D. A. Bloom, and A. K. Jaiswal, "Nuclear import and export signals in control of Nrf2," The Journal of Biological Chemistry, vol. 280, no. 32, pp. 29158-29168, 2005.

[23] K. Itoh, K. I. Tong, and M. Yamamoto, "Molecular mechanism activating Nrf2-Keap1 pathway in regulation of adaptive response to electrophiles," Free Radical Biology \& Medicine, vol. 36, no. 10, pp. 1208-1213, 2004.

[24] K. I. Tong, Y. Katoh, H. Kusunoki, K. Itoh, T. Tanaka, and M. Yamamoto, "Keap1 recruits Neh2 through binding to ETGE and DLG motifs: characterization of the two-site molecular recognition model," Molecular and Cellular Biology, vol. 26, no. 8, pp. 2887-2900, 2006.

[25] K. Itoh, N. Wakabayashi, Y. Katoh et al., "Keap1 represses nuclear activation of antioxidant responsive elements by Nrf2 through binding to the amino-terminal Neh2 domain," Genes \& Development, vol. 13, no. 1, pp. 76-86, 1999.

[26] D. D. Zhang, S. C. Lo, J. V. Cross, D. J. Templeton, and M. Hannink, "Keap1 is a redox-regulated substrate adaptor protein for a Cul3-dependent ubiquitin ligase complex," Molecular and Cellular Biology, vol. 24, no. 24, pp. 1094110953, 2004.

[27] Y. Katoh, K. Itoh, E. Yoshida, M. Miyagishi, A. Fukamizu, and M. Yamamoto, "Two domains of Nrf2 cooperatively bind CBP, a CREB binding protein, and synergistically activate transcription," Genes to Cells: Devoted to Molecular \& Cellular Mechanisms, vol. 6, no. 10, pp. 857-868, 2001.

[28] M. McMahon, N. Thomas, K. Itoh, M. Yamamoto, and J. D. Hayes, "Redox-regulated turnover of Nrf2 is determined by 
at least two separate protein domains, the redox-sensitive Neh2 degron and the redox-insensitive Neh6 degron," The Journal of Biological Chemistry, vol. 279, no. 30, pp. 3155631567, 2004.

[29] H. Wang, K. Liu, M. Geng et al., "RXRalpha inhibits the NRF2-ARE signaling pathway through a direct interaction with the Neh7 domain of NRF2," Cancer Research, vol. 73, no. 10, pp. 3097-3108, 2013.

[30] N. Wakabayashi, A. T. Dinkova-Kostova, W. D. Holtzclaw et al., "Protection against electrophile and oxidant stress by induction of the phase 2 response: fate of cysteines of the Keap1 sensor modified by inducers," Proceedings of the National Academy of Sciences of the United States of America, vol. 101, no. 7, pp. 2040-2045, 2004.

[31] L. M. Zipper and R. T. Mulcahy, "The Keap1 BTB/POZ dimerization function is required to sequester $\mathrm{Nrf} 2$ in cytoplasm," The Journal of Biological Chemistry, vol. 277, no. 39, pp. 36544-36552, 2002.

[32] N. Chauhan, L. Chaunsali, P. Deshmukh, and B. Padmanabhan, "Analysis of dimerization of BTB-IVR domains of Keap1 and its interaction with Cul3, by molecular modeling," Bioinformation, vol. 9, no. 9, pp. 450-455, 2013.

[33] A. T. Dinkova-Kostova, W. D. Holtzclaw, R. N. Cole et al., "Direct evidence that sulfhydryl groups of Keap1 are the sensors regulating induction of phase 2 enzymes that protect against carcinogens and oxidants," Proceedings of the National Academy of Sciences of the United States of America, vol. 99, no. 18, pp. 11908-11913, 2002.

[34] W. Hur and N. S. Gray, "Small molecule modulators of antioxidant response pathway," Current Opinion in Chemical Biology, vol. 15, no. 1, pp. 162-173, 2011.

[35] R. Saito, T. Suzuki, K. Hiramoto et al., "Characterizations of three major cysteine sensors of Keap1 in stress response," Molecular and Cellular Biology, vol. 36, no. 2, pp. 271-284, 2015.

[36] K. Takaya, T. Suzuki, H. Motohashi et al., "Validation of the multiple sensor mechanism of the Keap1-Nrf2 system," Free Radical Biology \& Medicine, vol. 53, no. 4, pp. 817-827, 2012.

[37] A. Uruno and H. Motohashi, "The Keap1-Nrf2 system as an in vivo sensor for electrophiles," Nitric Oxide : Biology and Chemistry, vol. 25, no. 2, pp. 153-160, 2011.

[38] J. D. Hayes and M. McMahon, "NRF2 and KEAP1 mutations: permanent activation of an adaptive response in cancer," Trends in Biochemical Sciences, vol. 34, no. 4, pp. 176-188, 2009.

[39] Y. Katoh, K. Iida, M. I. Kang et al., "Evolutionary conserved N-terminal domain of Nrf2 is essential for the Keap1mediated degradation of the protein by proteasome," Archives of Biochemistry and Biophysics, vol. 433, no. 2, pp. 342-350, 2005.

[40] D. Stewart, E. Killeen, R. Naquin, S. Alam, and J. Alam, "Degradation of transcription factor Nrf2 via the ubiquitinproteasome pathway and stabilization by cadmium," The Journal of Biological Chemistry, vol. 278, no. 4, pp. 23962402, 2003.

[41] K. J. Min, J. H. Kim, I. Jou, and E. H. Joe, “Adenosine induces hemeoxygenase-1 expression in microglia through the activation of phosphatidylinositol 3-kinase and nuclear factor E2related factor 2," Glia, vol. 56, no. 9, pp. 1028-1037, 2008.

[42] S. Kalayarasan, P. N. Prabhu, N. Sriram, R. Manikandan, M. Arumugam, and G. Sudhandiran, "Diallyl sulfide enhances antioxidants and inhibits inflammation through the activation of Nrf2 against gentamicin-induced nephrotoxicity in Wistar rats," European Journal of Pharmacology, vol. 606, no. 1-3, pp. 162-171, 2009.

[43] S. Ruiz, P. E. Pergola, R. A. Zager, and N. D. Vaziri, "Targeting the transcription factor Nrf2 to ameliorate oxidative stress and inflammation in chronic kidney disease," Kidney International, vol. 83, no. 6, pp. 1029-1041, 2013.

[44] B. Harder, T. Jiang, T. Wu et al., "Molecular mechanisms of Nrf2 regulation and how these influence chemical modulation for disease intervention," Biochemical Society Transactions, vol. 43, no. 4, pp. 680-686, 2015.

[45] M. K. Kwak, K. Itoh, M. Yamamoto, and T. W. Kensler, "Enhanced expression of the transcription factor Nrf2 by cancer chemopreventive agents: role of antioxidant response element-like sequences in the nrf2 promoter," Molecular and Cellular Biology, vol. 22, no. 9, pp. 28832892, 2002.

[46] X. Cheng, C. H. Ku, and R. C. Siow, "Regulation of the Nrf2 antioxidant pathway by microRNAs: new players in micromanaging redox homeostasis," Free Radical Biology \& Medicine, vol. 64 no. 9, pp. 4-11, 2013.

[47] M. Yang, Y. Yao, G. Eades, Y. Zhang, and Q. Zhou, "MiR-28 regulates Nrf2 expression through a Keap1-independent mechanism," Breast Cancer Research and Treatment, vol. 129, no. 3, pp. 983-991, 2011.

[48] N. Li, S. Muthusamy, R. Liang, H. Sarojini, and E. Wang, "Increased expression of miR-34a and miR-93 in rat liver during aging, and their impact on the expression of Mgst1 and Sirt1," Mechanisms of Ageing and Development, vol. 132, no. 3, pp. 75-85, 2011.

[49] A. Stachurska, M. Ciesla, M. Kozakowska et al., "Cross-talk between microRNAs, nuclear factor E2-related factor 2, and heme oxygenase-1 in ochratoxin A-induced toxic effects in renal proximal tubular epithelial cells," Molecular Nutrition \& Food Research, vol. 57, no. 3, pp. 504-515, 2013.

[50] G. Eades, M. Yang, Y. Yao, Y. Zhang, and Q. Zhou, "miR200a regulates Nrf2 activation by targeting Keap1 mRNA in breast cancer cells," The Journal of Biological Chemistry, vol. 286, no. 47, pp. 40725-40733, 2011.

[51] T. O. Khor, Y. Huang, T. Y. Wu, L. Shu, J. Lee, and A. N. Kong, "Pharmacodynamics of curcumin as DNA hypomethylation agent in restoring the expression of Nrf2 via promoter CpGs demethylation," Biochemical Pharmacology, vol. 82, no. 9, pp. 1073-1078, 2011.

[52] C. Zhang, Z. Y. Su, T. O. Khor, L. Shu, and A. N. Kong, "Sulforaphane enhances Nrf2 expression in prostate cancer TRAMP C1 cells through epigenetic regulation," Biochemical Pharmacology, vol. 85, no. 9, pp. 1398-1404, 2013.

[53] F. Correa, C. Mallard, M. Nilsson, and M. Sandberg, "Activated microglia decrease histone acetylation and Nrf2inducible anti-oxidant defence in astrocytes: restoring effects of inhibitors of HDACs, p38 MAPK and GSK3beta," Neurobiology of Disease, vol. 44, no. 1, pp. 142-151, 2011.

[54] Z. Li, L. Xu, N. Tang et al., "The polycomb group protein EZH2 inhibits lung cancer cell growth by repressing the transcription factor Nrf2," FEBS Letters, vol. 588, no. 17, pp. 3000-3007, 2014.

[55] Y. Guo, S. Yu, C. Zhang, and A. N. Kong, "Epigenetic regulation of Keap1-Nrf2 signaling," Free Radical Biology \& Medicine, vol. 88, no. Pt B, pp. 337-349, 2015. 
[56] N. F. Villeneuve, A. Lau, and D. D. Zhang, "Regulation of the Nrf2-Keap1 antioxidant response by the ubiquitin proteasome system: an insight into cullin-ring ubiquitin ligases," Antioxidants \& Redox Signaling, vol. 13, no. 11, pp. 16991712, 2010.

[57] W. Cui, B. Li, Y. Bai et al., "Potential role for Nrf2 activation in the therapeutic effect of MG132 on diabetic nephropathy in OVE26 diabetic mice," American Journal of Physiology Endocrinology and Metabolism, vol. 304, no. 1, pp. E87E99, 2013.

[58] A. Lau, X. J. Wang, F. Zhao et al., "A noncanonical mechanism of Nrf2 activation by autophagy deficiency: direct interaction between Keap1 and p62," Molecular and Cellular Biology, vol. 30, no. 13, pp. 3275-3285, 2010.

[59] H. C. Huang, T. Nguyen, and C. B. Pickett, "Phosphorylation of Nrf2 at Ser-40 by protein kinase C regulates antioxidant response element-mediated transcription," The Journal of Biological Chemistry, vol. 277, no. 45, pp. 42769-42774, 2002.

[60] M. Miyazawa and Y. Tsuji, "Evidence for a novel antioxidant function and isoform-specific regulation of the human p66Shc gene," Molecular Biology of the Cell, vol. 25, no. 13, pp. 2116-2127, 2014.

[61] T. Miyata, N. Suzuki, and C. van Ypersele de Strihou, "Diabetic nephropathy: are there new and potentially promising therapies targeting oxygen biology?" Kidney International, vol. 84, no. 4, pp. 693-702, 2013.

[62] Q. Sun, Z. Y. Shen, Q. T. Meng, H. Z. Liu, W. N. Duan, and Z. Y. Xia, "The role of DJ-1/Nrf2 pathway in the pathogenesis of diabetic nephropathy in rats," Renal Failure, vol. 38, no. 2, pp. 294-304, 2016.

[63] K. Yoh, A. Hirayama, K. Ishizaki et al., "Hyperglycemia induces oxidative and nitrosative stress and increases renal functional impairment in Nrf2-deficient mice," Genes to Cells : Devoted to Molecular \& Cellular Mechanisms, vol. 13, no. 11, pp. 1159-1170, 2008.

[64] T. Jiang, Z. Huang, Y. Lin, Z. Zhang, D. Fang, and D. D. Zhang, "The protective role of Nrf2 in streptozotocininduced diabetic nephropathy," Diabetes, vol. 59, no. 4, pp. 850-860, 2010.

[65] B. H. Choi, K. S. Kang, and M. K. Kwak, "Effect of redox modulating NRF2 activators on chronic kidney disease," Molecules, vol. 19, no. 8, pp. 12727-12759, 2014.

[66] N. Wakabayashi, K. Itoh, J. Wakabayashi et al., "Keap1-null mutation leads to postnatal lethality due to constitutive Nrf2 activation," Nature Genetics, vol. 35, no. 3, pp. 238245, 2003.

[67] V. R. More, J. Xu, P. C. Shimpi et al., "Keap1 knockdown increases markers of metabolic syndrome after long-term high fat diet feeding," Free Radical Biology \& Medicine, vol. 61 no. 8, pp. 85-94, 2013.

[68] Y. K. Zhang, K. C. Wu, J. Liu, and C. D. Klaassen, "Nrf2 deficiency improves glucose tolerance in mice fed a high-fat diet," Toxicology and Applied Pharmacology, vol. 264, no. 3, pp. 305-314, 2012.

[69] J. Xu, S. R. Kulkarni, A. C. Donepudi, V. R. More, and A. L. Slitt, "Enhanced Nrf2 activity worsens insulin resistance, impairs lipid accumulation in adipose tissue, and increases hepatic steatosis in leptin-deficient mice," Diabetes, vol. 61, no. 12, pp. 3208-3218, 2012.

[70] M. S. Yates, Q. T. Tran, P. M. Dolan et al., "Genetic versus chemoprotective activation of Nrf2 signaling: overlapping yet distinct gene expression profiles between Keap1 knockout and triterpenoid-treated mice," Carcinogenesis, vol. 30, no. 6, pp. 1024-1031, 2009.

[71] X. Wang, X. Zhao, T. Feng, G. Jin, and Z. Li, "Rutin prevents high glucose-induced renal glomerular endothelial hyperpermeability by inhibiting the ROS/Rhoa/ROCK signaling pathway," Planta Medica, vol. 82, no. 14, pp. 1252-1257, 2016.

[72] X. Zhang, H. He, D. Liang et al., "Protective effects of berberine on renal injury in streptozotocin (STZ)-induced diabetic mice," International Journal of Molecular Sciences, vol. 17, no. 8, p. 1327, 2016.

[73] W. Gong, C. Chen, F. Xiong et al., "CKIP-1 ameliorates high glucose-induced expression of fibronectin and intercellular cell adhesion molecule- 1 by activating the Nrf2/ARE pathway in glomerular mesangial cells," Biochemical Pharmacology, vol. 116 no. 9, pp. 140-152, 2016.

[74] M. M. Hussein and M. K. Mahfouz, "Effect of resveratrol and rosuvastatin on experimental diabetic nephropathy in rats," Biomedicine \& Pharmacotherapy = Biomedecine \& Pharmacotherapie, vol. 82 no. 8, pp. 685-692, 2016.

[75] P. Wu, Y. Yan, L. L. Ma et al., "Effects of the Nrf2 protein modulator salvianolic acid A alone or combined with metformin on diabetes-associated macrovascular and renal injury," The Journal of Biological Chemistry, vol. 291, no. 42, pp. 22288-22301, 2016.

[76] Q. Yin, Y. Xia, and G. Wang, "Sinomenine alleviates high glucose-induced renal glomerular endothelial hyperpermeability by inhibiting the activation of RhoA/ROCK signaling pathway," Biochemical and Biophysical Research Communications, vol. 477, no. 4, pp. 881-886, 2016.

[77] M. Raish, A. Ahmad, B. L. Jan et al., "Momordica charantia polysaccharides mitigate the progression of STZ induced diabetic nephropathy in rats," International Journal of Biological Macromolecules, vol. 91 no. 10, pp. 394-399, 2016.

[78] B. H. Kim, E. S. Lee, R. Choi et al., "Protective effects of curcumin on renal oxidative stress and lipid metabolism in a rat model of type 2 diabetic nephropathy," Yonsei Medical Journal, vol. 57, no. 3, pp. 664-673, 2016.

[79] Y. Yang, G. Chen, X. Cheng et al., "Therapeutic potential of digitoflavone on diabetic nephropathy: nuclear factor erythroid 2-related factor 2-dependent anti-oxidant and antiinflammatory effect," Scientific Reports, vol. 5 no. 6, p. 12377, 2015.

[80] X. Zhang, D. Liang, L. Guo et al., "Curcumin protects renal tubular epithelial cells from high glucose-induced epithelialto-mesenchymal transition through Nrf2-mediated upregulation of heme oxygenase-1," Molecular Medicine Reports, vol. 12, no. 1, pp. 1347-1355, 2015.

[81] L. Zhou, D. Y. Xu, W. G. Sha et al., "High glucose induces renal tubular epithelial injury via Sirt1/NF-kappaB/microR29/Keap1 signal pathway," Journal of Translational Medicine, vol. 13 no. 11, p. 352, 2015.

[82] S. M. Yang, S. M. Ka, H. L. Wu et al., "Thrombomodulin domain 1 ameliorates diabetic nephropathy in mice via anti-NF-kappaB/NLRP3 inflammasome-mediated inflammation, enhancement of NRF2 antioxidant activity and inhibition of apoptosis," Diabetologia, vol. 57, no. 2, pp. 424434, 2014.

[83] K. Nakai, H. Fujii, K. Kono et al., "Vitamin D activates the Nrf2-Keap1 antioxidant pathway and ameliorates nephropathy in diabetic rats," American Journal of Hypertension, vol. 27, no. 4, pp. 586-595, 2014. 
[84] B. Jiang, L. Guo, B. Y. Li et al., "Resveratrol attenuates early diabetic nephropathy by down-regulating glutathione stransferases Mu in diabetic rats," Journal of Medicinal Food, vol. 16, no. 6, pp. 481-486, 2013.

[85] W. Cui, Y. Bai, X. Miao et al., "Prevention of diabetic nephropathy by sulforaphane: possible role of Nrf2 upregulation and activation," Oxidative Medicine and Cellular Longevity, vol. 2012 no. 9, p. 821936, 2012.

[86] H. Zheng, S. A. Whitman, W. Wu et al., "Therapeutic potential of $\mathrm{Nrf2}$ activators in streptozotocin-induced diabetic nephropathy," Diabetes, vol. 60, no. 11, pp. 30553066, 2011.

[87] P. Palsamy and S. Subramanian, "Resveratrol protects diabetic kidney by attenuating hyperglycemia-mediated oxidative stress and renal inflammatory cytokines via Nrf2-Keap1 signaling," Biochimica et Biophysica Acta, vol. 1812, no. 7, pp. 719-731, 2011.

[88] Z. F. Luo, B. Feng, J. Mu et al., "Effects of 4-phenylbutyric acid on the process and development of diabetic nephropathy induced in rats by streptozotocin: regulation of endoplasmic reticulum stress-oxidative activation," Toxicology and Applied Pharmacology, vol. 246, no. 1-2, pp. 49-57, 2010.

[89] H. Wu, L. Kong, Y. Cheng et al., "Metallothionein plays a prominent role in the prevention of diabetic nephropathy by sulforaphane via up-regulation of Nrf2," Free Radical Biology \& Medicine, vol. 89 no. 12, pp. 431-442, 2015.

[90] W. Dong, Y. Jia, X. Liu et al., "Sodium butyrate activates NRF2 to ameliorate diabetic nephropathy possibly via inhibition of HDAC," The Journal of Endocrinology, vol. 232, no. 1, pp. 71-83, 2017.

[91] Z. Chen, X. Xie, J. Huang et al., "Connexin43 regulates high glucose-induced expression of fibronectin, ICAM-1 and TGF-betal via Nrf2/ARE pathway in glomerular mesangial cells," Free Radical Biology \& Medicine, vol. 102 no. 1, pp. 77-86, 2017.

[92] K. Shahzad, F. Bock, M. M. Al-Dabet et al., "Stabilization of endogenous Nrf2 by minocycline protects against Nlrp3inflammasome induced diabetic nephropathy," Scientific Reports, vol. 6 no. 10, p. 34228, 2016.

[93] H. Wu, L. Kong, Y. Tan et al., "C66 ameliorates diabetic nephropathy in mice by both upregulating NRF2 function via increase in miR-200a and inhibiting miR-21," Diabetologia, vol. 59, no. 7, pp. 1558-1568, 2016.

[94] A. S. Arellano-Buendia, M. Tostado-Gonzalez, F. E. GarciaArroyo et al., "Anti-inflammatory therapy modulates Nrf2Keap1 in kidney from rats with diabetes," Oxidative Medicine and Cellular Longevity, vol. 2016 no. 2, p. 4693801, 2016.

[95] Y. Cheng, J. Zhang, W. Guo et al., "Up-regulation of Nrf2 is involved in FGF21-mediated fenofibrate protection against type 1 diabetic nephropathy," Free Radical Biology \& Medicine, vol. 93 no. 4, pp. 94-109, 2016.

[96] G. Shang, X. Tang, P. Gao et al., "Sulforaphane attenuation of experimental diabetic nephropathy involves GSK-3 beta/Fyn/ Nrf2 signaling pathway," The Journal of Nutritional Biochemistry, vol. 26, no. 6, pp. 596-606, 2015.

[97] K. Huang, C. Chen, J. Hao et al., "Polydatin promotes Nrf2ARE anti-oxidative pathway through activating Sirt1 to resist AGEs-induced upregulation of fibronetin and transforming growth factor-betal in rat glomerular messangial cells," Molecular and Cellular Endocrinology, vol. 399 no. 1, pp. 178-189, 2015.
[98] B. Li, W. Cui, Y. Tan et al., "Zinc is essential for the transcription function of Nrf2 in human renal tubule cells in vitro and mouse kidney in vivo under the diabetic condition," Journal of Cellular and Molecular Medicine, vol. 18, no. 5, pp. 895906, 2014.

[99] X. Zhang, Y. Zhao, Q. Chu, Z. Y. Wang, H. Li, and Z. H. Chi, "Zinc modulates high glucose-induced apoptosis by suppressing oxidative stress in renal tubular epithelial cells," Biological Trace Element Research, vol. 158, no. 2, pp. 259-267, 2014.

[100] X. Zhou, Y. Feng, Z. Zhan, and J. Chen, "Hydrogen sulfide alleviates diabetic nephropathy in a streptozotocin-induced diabetic rat model," The Journal of Biological Chemistry, vol. 289, no. 42, pp. 28827-28834, 2014.

[101] K. Huang, J. Huang, X. Xie et al., "Sirt1 resists advanced glycation end products-induced expressions of fibronectin and TGF-beta1 by activating the Nrf2/ARE pathway in glomerular mesangial cells," Free Radical Biology \& Medicine, vol. 65 no. 12, pp. 528-540, 2013.

[102] X. Xing, C. Zhang, M. Shao et al., "Low-dose radiation activates Akt and Nrf2 in the kidney of diabetic mice: a potential mechanism to prevent diabetic nephropathy," Oxidative Medicine and Cellular Longevity, vol. 2012 no. 11, p. 291087, 2012.

[103] S. Guoguo, T. Akaike, J. Tao, C. Qi, Z. Nong, and L. Hui, "HGF-mediated inhibition of oxidative stress by 8-nitrocGMP in high glucose-treated rat mesangial cells," Free Radical Research, vol. 46, no. 10, pp. 1238-1248, 2012.

[104] H. Fujita, H. Fujishima, T. Morii et al., "Modulation of renal superoxide dismutase by telmisartan therapy in C57BL/6Ins2(Akita) diabetic mice," Hypertension Research : Official Journal of the Japanese Society of Hypertension, vol. 35, no. 2, pp. 213-220, 2012.

[105] H. Li, L. Zhang, F. Wang et al., "Attenuation of glomerular injury in diabetic mice with tert-butylhydroquinone through nuclear factor erythroid 2-related factor 2-dependent antioxidant gene activation," American Journal of Nephrology, vol. 33, no. 4, pp. 289-297, 2011.

[106] Z. F. Luo, W. Qi, B. Feng et al., "Prevention of diabetic nephropathy in rats through enhanced renal antioxidative capacity by inhibition of the proteasome," Life Sciences, vol. 88, no. 11-12, pp. 512-520, 2011.

[107] J. Wei, Y. Zhang, Y. Luo et al., “Aldose reductase regulates miR-200a-3p/141-3p to coordinate Keap1-Nrf2, Tgfbeta1/2, and Zeb1/2 signaling in renal mesangial cells and the renal cortex of diabetic mice," Free Radical Biology \& Medicine, vol. 67 no. 2, pp. 91-102, 2014.

[108] M. C. Haigis and L. P. Guarente, "Mammalian sirtuins-emerging roles in physiology, aging, and calorie restriction," Genes \& Development, vol. 20, no. 21, pp. 2913-2921, 2006.

[109] D. Yang, X. Tan, Z. Lv et al., "Regulation of Sirt1/Nrf2/TNFalpha signaling pathway by luteolin is critical to attenuate acute mercuric chloride exposure induced hepatotoxicity," Scientific Reports, vol. 6 no. 11, p. 37157, 2016.

[110] X. Xia, B. Qu, Y. M. Li et al., "NFAT5 protects astrocytes against oxygen-glucose-serum deprivation/restoration damage via the SIRT1/Nrf2 pathway," Journal of Molecular Neuroscience: $M N$, vol. 61, no. 1, pp. 96-104, 2016.

[111] S. A. Shah, M. Khan, M. H. Jo, M. G. Jo, F. U. Amin, and M. O. Kim, "Melatonin stimulates the SIRT1/Nrf2 signaling pathway counteracting lipopolysaccharide (LPS)-induced 
oxidative stress to rescue postnatal rat brain," CNS Neuroscience \& Therapeutics, vol. 23, no. 1, pp. 33-44, 2016.

[112] A. Cao, L. Wang, X. Chen et al., "Ursodeoxycholic acid ameliorated diabetic nephropathy by attenuating hyperglycemiamediated oxidative stress," Biological \& Pharmaceutical Bulletin, vol. 39, no. 8, pp. 1300-1308, 2016.

[113] C. Wang, C. Li, H. Peng et al., "Activation of the Nrf2-ARE pathway attenuates hyperglycemia-mediated injuries in mouse podocytes," Cellular Physiology and Biochemistry: International Journal of Experimental Cellular Physiology, Biochemistry, and Pharmacology, vol. 34, no. 3, pp. 891902, 2014.

[114] X. Xu, J. Sun, X. Chang et al., "Genetic variants of nuclear factor erythroid-derived 2-like 2 associated with the complications in Han descents with type 2 diabetes mellitus of Northeast China," Journal of Cellular and Molecular Medicine, vol. 20, no. 11, pp. 2078-2088, 2016.

[115] K. T. Liby, M. M. Yore, and M. B. Sporn, “Triterpenoids and rexinoids as multifunctional agents for the prevention and treatment of cancer," Nature Reviews Cancer, vol. 7, no. 5, pp. 357-369, 2007.

[116] K. T. Liby and M. B. Sporn, "Synthetic oleanane triterpenoids: multifunctional drugs with a broad range of applications for prevention and treatment of chronic disease," Pharmacological Reviews, vol. 64, no. 4, pp. 972-1003, 2012.

[117] S. Nagaraj, J. I. Youn, H. Weber et al., "Anti-inflammatory triterpenoid blocks immune suppressive function of MDSCs and improves immune response in cancer," Clinical Cancer Research : An Official Journal of the American Association for Cancer Research, vol. 16, no. 6, pp. 18121823, 2010.

[118] D. S. Hong, R. Kurzrock, J. G. Supko et al., "A phase I first-inhuman trial of bardoxolone methyl in patients with advanced solid tumors and lymphomas," Clinical Cancer Research : An Official Journal of the American Association for Cancer Research, vol. 18, no. 12, pp. 3396-3406, 2012.

[119] P. E. Pergola, M. Krauth, J. W. Huff et al., "Effect of bardoxolone methyl on kidney function in patients with T2D and stage 3b-4 CKD," American Journal of Nephrology, vol. 33, no. 5, pp. 469-476, 2011.

[120] P. E. Pergola, P. Raskin, R. D. Toto et al., "Bardoxolone methyl and kidney function in CKD with type 2 diabetes," The New England Journal of Medicine, vol. 365, no. 4, pp. 327-336, 2011.

[121] D. de Zeeuw, T. Akizawa, P. Audhya et al., "Bardoxolone methyl in type 2 diabetes and stage 4 chronic kidney disease," The New England Journal of Medicine, vol. 369, no. 26, pp. 2492-2503, 2013.

[122] M. P. Chin, D. Wrolstad, G. L. Bakris et al., "Risk factors for heart failure in patients with type 2 diabetes mellitus and stage 4 chronic kidney disease treated with bardoxolone methyl," Journal of Cardiac Failure, vol. 20, no. 12, pp. 953958, 2014.

[123] M. P. Chin, S. A. Reisman, G. L. Bakris et al., "Mechanisms contributing to adverse cardiovascular events in patients with type 2 diabetes mellitus and stage 4 chronic kidney disease treated with bardoxolone methyl," American Journal of Nephrology, vol. 39, no. 6, pp. 499508, 2014.

[124] S. Abdo, Y. Shi, A. Otoukesh et al., "Catalase overexpression prevents nuclear factor erythroid 2-related factor 2 stimulation of renal angiotensinogen gene expression, hypertension, and kidney injury in diabetic mice," Diabetes, vol. 63, no. 10, pp. 3483-3496, 2014.

[125] N. Noori, C. P. Kovesdy, R. Bross et al., "Novel equations to estimate lean body mass in maintenance hemodialysis patients," American Journal of Kidney Diseases : The Official Journal of the National Kidney Foundation, vol. 57, no. 1, pp. 130-139, 2011.

[126] S. S. Patel, M. Z. Molnar, J. A. Tayek et al., "Serum creatinine as a marker of muscle mass in chronic kidney disease: results of a cross-sectional study and review of literature," Journal of Cachexia, Sarcopenia and Muscle, vol. 4, no. 1, pp. 19-29, 2013.

[127] J. A. Tayek and K. Kalantar-Zadeh, "The extinguished BEACON of bardoxolone: not a Monday morning quarterback story," American Journal of Nephrology, vol. 37, no. 3, pp. 208-211, 2013.

[128] H. Yang, W. Xu, Z. Zhou et al., "Curcumin attenuates urinary excretion of albumin in type II diabetic patients with enhancing nuclear factor erythroid-derived 2-like 2 (Nrf2) system and repressing inflammatory signaling efficacies," Experimental and Clinical Endocrinology \& Diabetes : Official Journal, German Society of Endocrinology [and] German Diabetes Association, vol. 123, no. 6, pp. 360-367, 2015.

[129] E. H. Kobayashi, T. Suzuki, R. Funayama et al., "Nrf2 suppresses macrophage inflammatory response by blocking proinflammatory cytokine transcription," Nature Communications, vol. 7 no. 5, p. 11624, 2016.

[130] P. Gao, L. Li, L. Ji et al., "Nrf2 ameliorates diabetic nephropathy progression by transcriptional repression of TGFbetal through interactions with c-Jun and SP1," Biochimica et Biophysica Acta, vol. 1839, no. 11, pp. 1110-1120, 2014.

[131] C. Zoja, D. Corna, V. Nava et al., "Analogs of bardoxolone methyl worsen diabetic nephropathy in rats with additional adverse effects," American Journal of Physiology Renal Physiology, vol. 304, no. 6, pp. F808-F819, 2013.

[132] N. D. Vaziri, S. Liu, S. H. Farzaneh, S. Nazertehrani, M. Khazaeli, and Y. Y. Zhao, "Dose-dependent deleterious and salutary actions of the Nrf2 inducer dh404 in chronic kidney disease," Free Radical Biology \& Medicine, vol. 86 no. 9, pp. 374-381, 2015.

[133] S. M. Tan, A. Sharma, N. Stefanovic et al., "Derivative of bardoxolone methyl, dh404, in an inverse dose-dependent manner lessens diabetes-associated atherosclerosis and improves diabetic kidney disease," Diabetes, vol. 63, no. 9, pp. 3091-3103, 2014.

[134] S. Menegon, A. Columbano, and S. Giordano, "The dual roles of NRF2 in cancer," Trends in Molecular Medicine, vol. 22, no. 7, pp. 578-593, 2016.

[135] J. Kim and Y. S. Keum, "NRF2, a key regulator of antioxidants with two faces towards cancer," Oxidative Medicine and Cellular Longevity, vol. 2016 no. 6, p. 2746457, 2016.

[136] A. Ooi and K. A. Furge, "Fumarate hydratase inactivation in renal tumors: HIF1alpha, NRF2, and "cryptic targets" of transcription factors," Chinese Journal of Cancer, vol. 31, no. 9, pp. 413-420, 2012.

[137] S. K. Niture and A. K. Jaiswal, "Nrf2-induced antiapoptotic Bcl-xL protein enhances cell survival and drug resistance," Free Radical Biology \& Medicine, vol. 57 no. 4, pp. 119131, 2013. 
[138] Y. Mitsuishi, K. Taguchi, Y. Kawatani et al., "Nrf2 redirects glucose and glutamine into anabolic pathways in metabolic reprogramming," Cancer Cell, vol. 22, no. 1, pp. 66-79, 2012.

[139] S. Abdo, S. L. Zhang, and J. S. Chan, "Reactive oxygen species and nuclear factor erythroid 2-related factor 2 activation in diabetic nephropathy: a hidden target," Journal of Diabetes \& Metabolism, vol. 6, no. 6, 2015. 


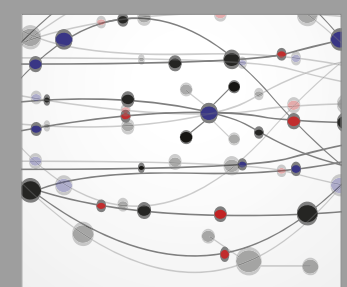

The Scientific World Journal
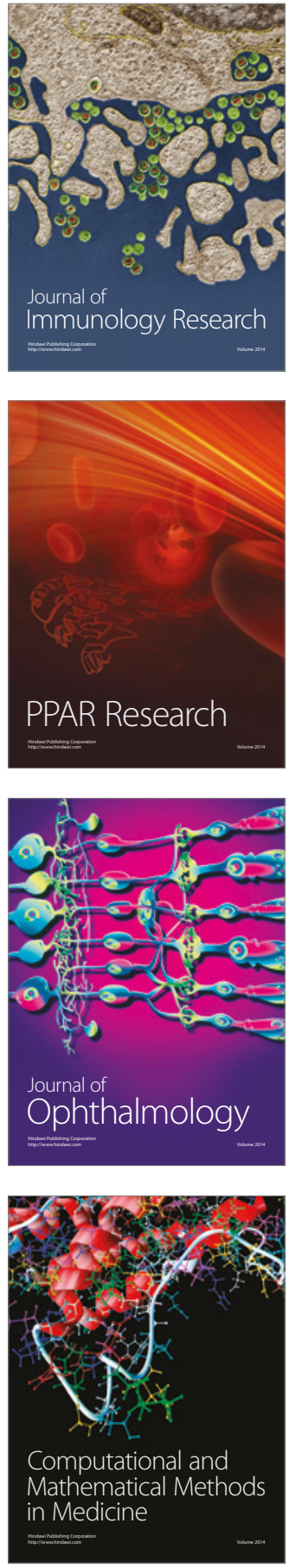

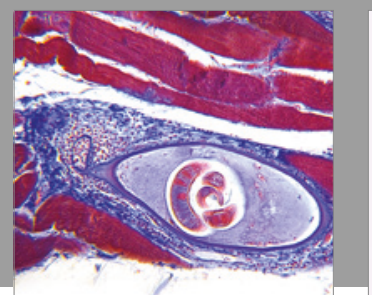

Gastroenterology Research and Practice
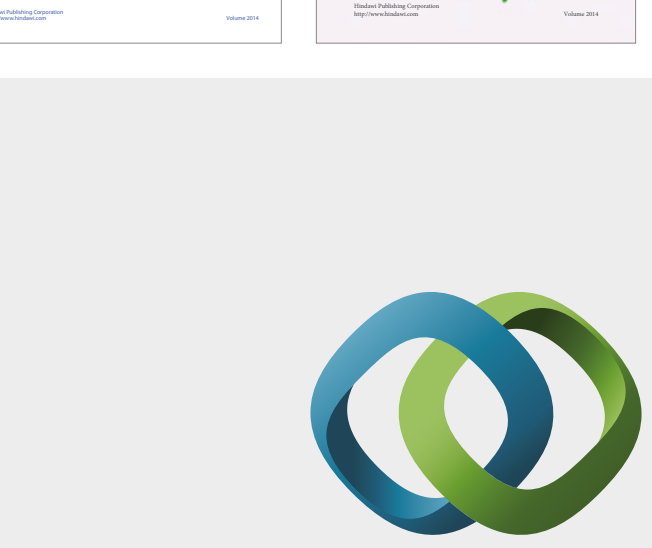

\section{Hindawi}

Submit your manuscripts at

https://www.hindawi.com
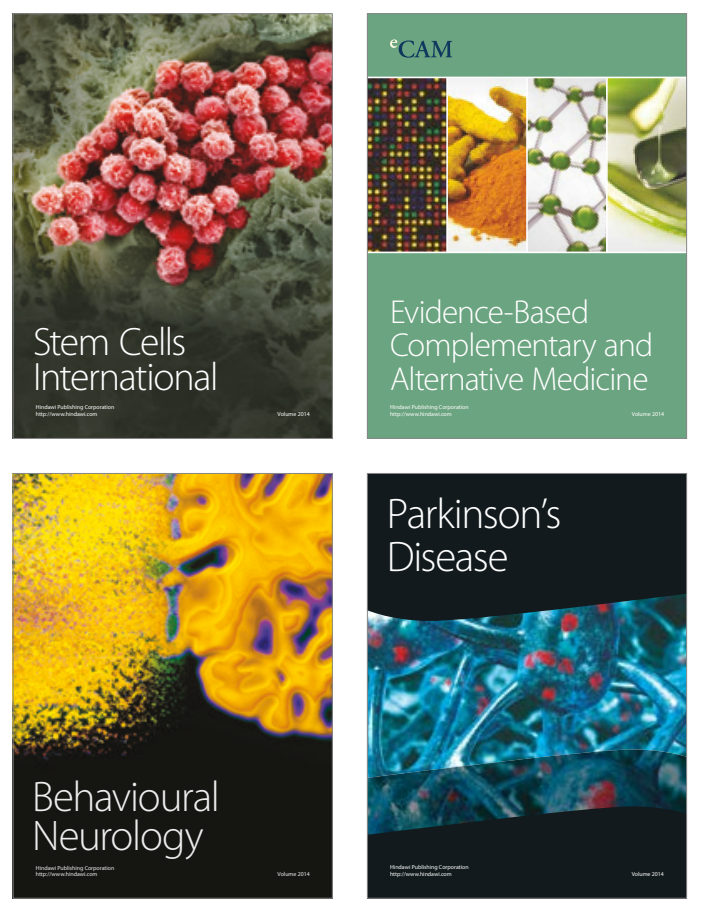
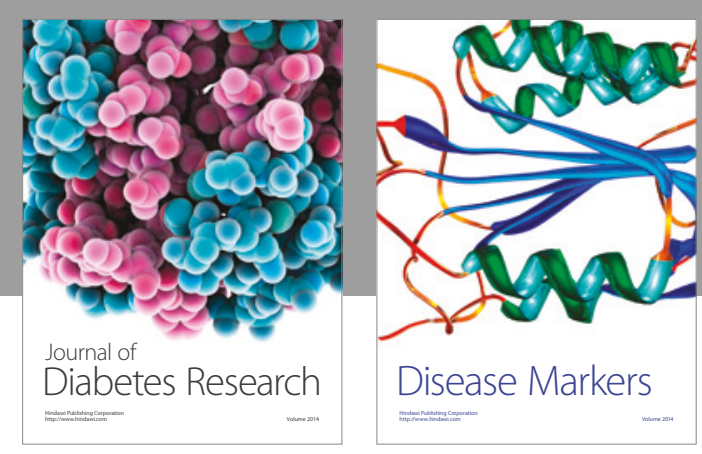

Disease Markers
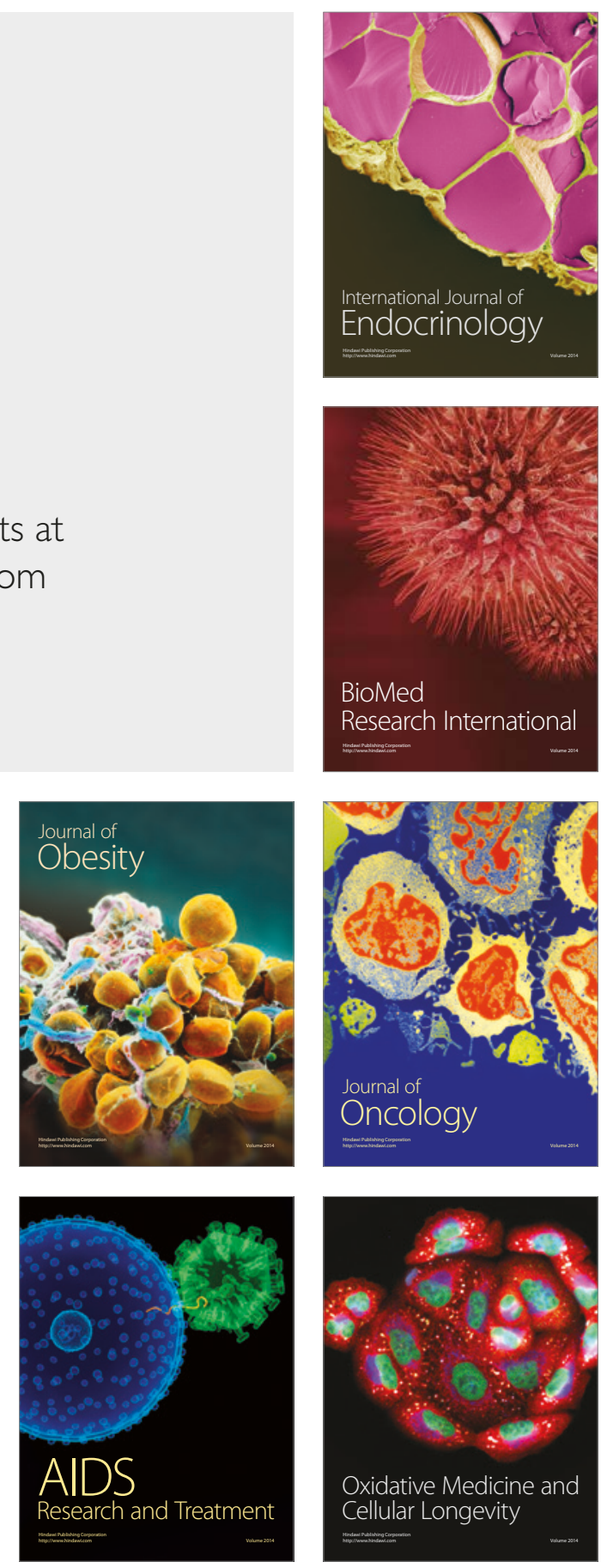